\title{
The Care of Patients With Colon Cancer
}

\author{
Current Treatment, and Evaluation of New Surgical Approaches
}

Rainer Kube, Ingo Gastinger, Pawel Mroczkowski, Henry Ptok, Steffanie Wolff, Hans Lippert

\section{SUMMARY}

Background: Multi-center observational studies in surgery can yield important findings, as long as they are appropriately designed and monitored and employ modern methods of statistical analysis.

Methods: In a multi-center quality assurance study carried out in 346 German hospitals from 2000 to 2004, data were collected from a total of 31055 patients who underwent surgery for colon carcinoma. The current, overall state of medical care for this disease was analyzed, with particular attention to aspects of quality assurance.

Results: $46.7 \%$ of the patients were in the advanced, prognostically unfavorable stages UICC III and IV and had an overall 5-year survival of $53.8 \%$ in stage III and $9.8 \%$ in stage IV. Laparoscopic intention-to-treat procedures were performed on 1401 patients (4.7\%), of whom $20.6 \%$ required conversion to laparotomy. The patients who required conversion to laparotomy had a worse overall outcome. 28271 patients were treated with tumor resection and primary anastomosis; in this group, $3 \%(n=844)$ developed an anastomotic leak. Logistic regression analysis identified the following risk factors for anastomotic leakage: duration of surgery, ileus, tumor localization in the left colon, and single-layer suturing.

Conclusion: This multi-center observational study yields valid findings about the epidemiology and overall quality of medical care for colon carcinoma in Germany.

\section{Cite this as:}

Kube R, Gastinger I, Mroczkowski P, Ptok H, Wolff S, Lippert $\mathrm{H}$ : The care of patients with colon cancer: current treatment, and evaluation of new surgical approaches. Dtsch Arztebl Int 2011; 108(4): 41-6. DOI: 10.3238/arztebl.2011.0041
An-Institut für Qualitätssicherung in der operativen Medizin, Otto-von-GuerickeUniversität Magdeburg: PD Dr. med. Kube, Prof. Dr. med. Gastinger, Dr. med. Mroczkowski, PD Dr. med. Ptok, Prof. Dr. med. Lippert

Klinik für Chirurgie, Carl-Thiem-Klinikum Cottbus: PD Dr. med. Kube, Prof. Dr. med. Gastinger, PD Dr. med. Ptok

Klinik für Allgemein-, Viszeral- und Gefäßchirurgie, Otto-von-Guericke-Universität Magdeburg: Dr. med. Mroczkowski, PD Dr. med. Wolff, Prof. Dr. med. Lippert he importance of contributions made by multicenter observational studies to findings in surgery is now undisputed after many years of controversial discussion (1-4). Many questions about quality assurance aspects of surgical medicine, for example, can only be examined using this type of study as part of clinical health services research. Observational studies are often the means of choice when dealing with the collection of data over longer periods, for example, data about survival rates in oncology (5).

Appropriate study design and monitoring as well as the use of modern biostatistical methods are a prerequisite to prevent biased results in such investigations. Recent reports indicate that observational studies can be carried out under the same exacting and strict standards as randomized controlled studies $(3,4,6)$.

Risk stratification is an important basic prerequisite when comparing treatment results in non-selected patient collectives on the basis of registry data. Simple univariate comparison of results for operative mortality, for example, with no consideration of the risk profile can result in misleading statements and is therefore unreliable. It becomes apparent that different scoring systems such as the POSSUM score or the propensity score can be used as practical instruments for riskadjusted comparison of clinical results as part of benchmarking. Results using these systems are already available from the authors' working group (7).

To ensure external validity and quality of the data, voluntary participation and strictly anonymized handling of the data are important prerequisites. Study monitoring with extensive plausibility tests and checks of the completeness of the data are also very important $(2,12,13)$.

The results of these observational studies enable analysis of the current care and management of colon carcinoma, for example, and provide an image of reality. In addition, sufficiently high case numbers from a large number of hospitals with differing profiles can allow for immediate evaluation of surgical techniques. Furthermore, such studies can generate hypotheses that form the basis of planning of randomized studies.

\section{Methods}

From 1 January 2000, to 31 December 2004, 31055 patients who had undergone surgical treatment of colon 


\section{Distribution of UICC stages during the study}

\begin{tabular}{l|l|l|l|l|l|l} 
Tumor stage & Entire study n (\%) & \multicolumn{5}{|c|}{ Study course n (\%) } \\
\hline & & 2000 & 2001 & 2002 & 2003 & 2004 \\
\hline UICC 0 & $414(1.4)$ & $47(0.8)$ & $79(1.3)$ & $107(1.7)$ & $103(1.7)$ & $78(1.3)$ \\
\hline UICC I & $5487(18.0)$ & $960(15.8)$ & $1058(17.4)$ & $1111(17.8)$ & $1190(19.6)$ & $1168(19.5)$ \\
\hline UICC II & $9738(32.0)$ & $1978(32.6)$ & $1959(32.2)$ & $1974(31.6)$ & $1931(31.7)$ & $1896(31.7)$ \\
\hline UICC III & $8711(26.6)$ & $1791(29.5)$ & $1774(29.2)$ & $1815(29.1)$ & $1681(27.6)$ & $1650(27.6)$ \\
\hline UICC IV & $6122(20.1)$ & $1297(21.4)$ & $1215(20.0)$ & $1239(19.8)$ & $1179(19.4)$ & $1192(19.9)$ \\
\hline
\end{tabular}

UICC, Union Internationale Contre le Cancer

Overall survival

(probability) of patients with colon carcinoma dependent on tumor stage $(\mathrm{n}=17684)$

\section{FIGURE 1}

\section{Overall survival (probability)}

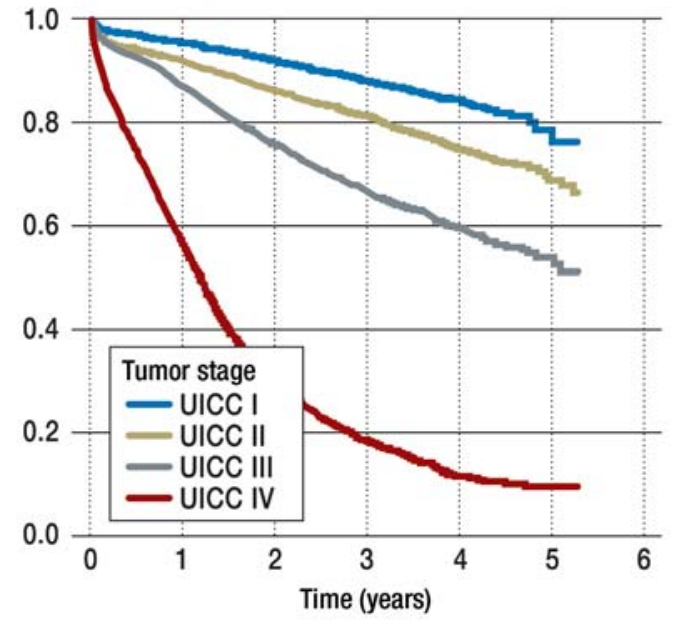

carcinoma were enrolled from 346 German hospitals providing all levels of health care. This was approximately $15 \%$ to $20 \%$ of all patients who underwent surgery in this period in Germany.

No participating hospital was excluded from the evaluation. As well as capturing perioperative data, a follow-up study with processing of oncological longterm results was carried out up to 31 December 2008. The follow-up rate was $67.6 \%$ of all patients who had consented to collection of their follow-up data (n=17 684).

The data, which were collected using a standardized questionnaire, were analyzed using the statistical program SPSS 12.0. A detailed description of the methodology and of partial results from the entire study have already been published $(12,14,16,17,20)$. To prevent distortion due to selection bias and confounding effects, any potential confounding of the data was estimated and minimized using analytical strategies such as regression and stratification (8-11). For the case where there are more than two groups, unifactorial variance analyses (ANOVA) were carried out with a subsequent Tukey multiple comparison test. The overall survival and tumor-free survival were calculated using the Kaplan-Meier method. The survival rates specified are consequently probabilities. Differences in the survival curves were checked for significance using the log-rank test. Potential influencing factors on binary endpoints were examined using logistic regression (Cox regression analysis, Wald statistics). A stepwise forward analysis was used, that is, in the so-called $0^{\text {th }}$ step all covariables were evaluated and in the subsequent forward selection the influencing factors, for anastomotic leakage for example, were determined stepwise.

\section{Results \\ UICC stages}

There was no sustained shift in the distribution of the tumor stages towards prognostically more favorable stages over the course of the study (Table 1). Adjuvant chemotherapy was planned postoperatively for $72.4 \%$ $(n=6311)$ of the patients in UICC stage III (UICC, Union Internationale Contre le Cancer). The 5-year overall survival was determined for advanced tumor stages UICC III and VI as being 53.8\% and 9.8\%, respectively (Figure 1).

\section{Tumor localization}

The analysis revealed differences due to tumor localization in the colon in terms of right colon carcinomas (RCC) versus left colon carcinomas (LCC). Localizations, defined by embryology and blood supply to the bowel sections, affect the biological behavior of the tumors. RCCs were more common in women and with increasing age. RCCs had a higher prevalence of poorly differentiated, locally advanced carcinomas with an admittedly comparable overall probability of developing distant metastases. There were differences in the metastasis pattern (Table 2).

\section{Surgical procedure}

The surgical procedure was carried out with a high degree of conformance to guidelines. With a resection 
rate of $97.2 \%$, the proportion of radical surgical procedures was $93.5 \%$. Seventy-eight percent of all patients were curatively resected. Primary laparotomy was the standard surgical procedure. Treatment of $4.7 \%$ of the patients $(n=1401)$ was via laparoscopic access with the intent to use a laparoscopically-assisted procedure. For 288 of these patients, it was necessary to switch to an open procedure intraoperatively with a conversion rate of $20.6 \%$ (Table 3 ).

The highly selective mechanism observed meant that the group whose surgery was completed laparoscopically achieved better early postoperative and oncological results compared to the open procedure. Patients in the conversion group had, compared to the open and laparoscopically completed patients, both worse postoperative and worse oncological long-term results (Figure 2). There was also a significant correlation between annual case numbers and the conversion rate. In hospitals carrying out less than 10 procedures this rate was $24.6 \%$ compared to $17.1 \%$ in hospitals carrying out 10 to 19 laparoscopic procedures per year and $3.6 \%$ in hospitals carrying out more than 20 laparoscopic procedures per year.

However, no significant correlation between procedure frequency and early and late results could be found for the entire study of colon carcinoma compared to investigations of rectal carcinoma (15).

\section{Anastomotic leakage}

One of the problems that cannot be investigated for ethical or methodological reasons using experimental studies is the question of risk factors for the development of anastomotic leakage (AL) and its effects on perioperative and oncological results. 28271 colon carcinoma patients underwent tumor resection with primary anastomosis. Postoperative suture leakage occurred in $3 \%(n=844)$ of these cases. Analysis revealed an increase in mortality of a factor of $7.2 \mathrm{com}-$ pared to patients after colonic resections without leakage (18.6\% with AL versus $2.6 \%$ without $\mathrm{AL})(21)$. The presence of anastomotic leakage was associated in the present study with a significantly worse oncological long-term course. The probability of 5-year overall survival was significantly lower for patients following anastomotic leakage $(51.0 \%$ with $\mathrm{AL}$ versus $67.3 \%$ without AL). The poorer oncological long-term result for patients with anastomotic leakage is not only a consequence of perioperative mortality. The tumor-free
TABLE 2

Differences arising from tumor localization in the colon

\begin{tabular}{l|l|l|l}
\hline Parameter & RCC $^{1}$ & LCC $^{2}$ & p-value \\
\hline Sex female (\%) & 55.3 & 45.9 & $<0.001$ \\
\hline Average age (years) & 71 & 68.5 & $<0.001$ \\
\hline Tumor grade G1/G2 & 71.4 & 83 & $<0.001$ \\
\hline $\begin{array}{l}\text { Total incidence of } \\
\text { synchronous metastases } \\
\text { of which, hepatic } \\
\text { metastases } \\
\text { of which, peritoneal } \\
\text { carcinoses }\end{array}$ & 19.9 & 20.4 & 0.409 \\
\hline
\end{tabular}

${ }^{1}$ right colon carcinoma; ${ }^{2}$ left colon carcinoma

5-year survival probability in the group with anastomotic leakage was $63.0 \%$, which was significantly lower than in the group without anastomotic leakage $(74.6 \%, \mathrm{p}<0.001)$.

A logistic regression model, which was formed using forward selection, incorporates the risk factors, which are independent of each other, for the development of postoperative anastomotic leakage as listed in Table 4 in the order of their significance. Single-layer suturing is an independent risk factor in the multiple analysis for the development of anastomotic leakage. Of the tumorrelated covariables, tumor localization in the left colon is associated with a significantly higher leakage rate. In more advanced tumor stages, there is only a trend towards more leakages but the differences are not significant.

\section{Discussion}

The early postoperative and the oncological long-term results for surgical treatment of colon carcinoma can be determined using comprehensive, prospective, multicenter observational studies of evidence level $2 \mathrm{~b}$. These data represent the current care and management of these patients in routine clinical practice in Germany. As well as describing important epidemiological aspects, statements can be made about the evaluation of new surgical procedures and the assessment of specific surgical techniques.

\section{TABLE 3}

Laparoscopic procedure for colon carcinoma, period 2000 to 2004

\begin{tabular}{l|l|l|l|l|l|l|}
$\begin{array}{l}\text { Surgical } \\
\text { access }\end{array}$ & Entire study $n(\%)$ & \multicolumn{5}{c|}{ Study course $n(\%)$} \\
\hline & & 2000 & 2001 & 2002 & 2003 & 2004 \\
\hline Laparoscopic & $1401(4.5)$ & $184(3.0)$ & $232(3.7)$ & $275(4.3)$ & $305(4.9)$ & $405(6.7)$ \\
\hline Conversions & $288(20.6)$ & $36(19.6)$ & $52(22.4)$ & $64(23.3)$ & $60(19.7)$ & $76(18.8)$ \\
\hline
\end{tabular}




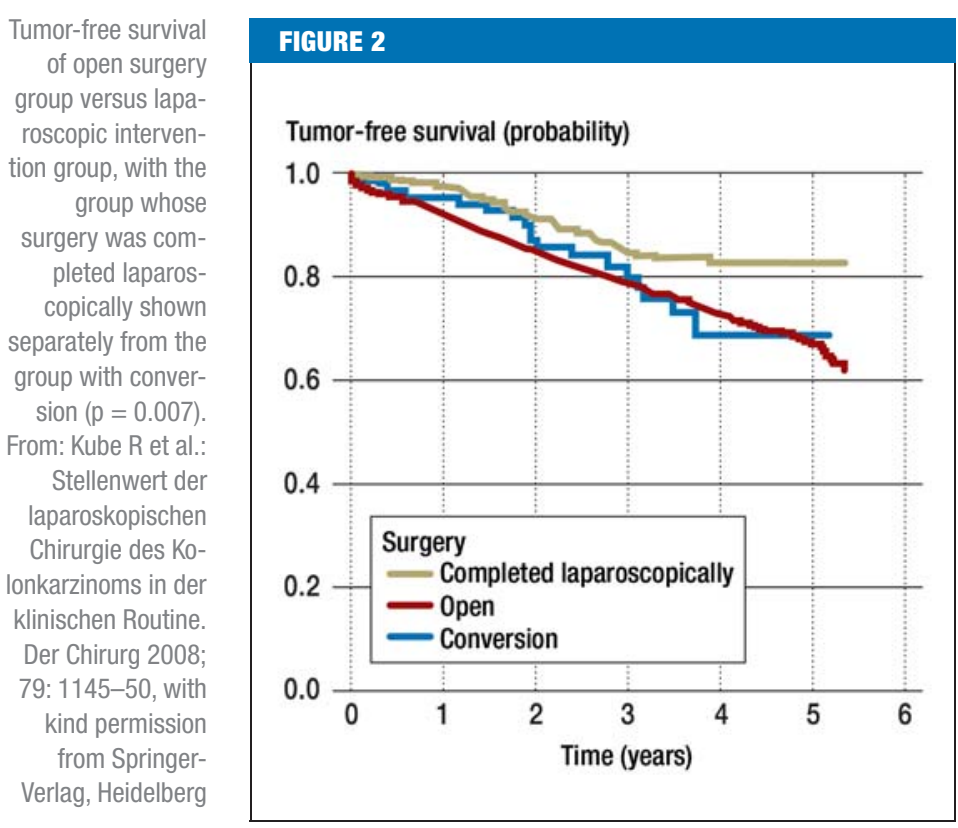

It must be stated, however, that the colonoscopy screening established during the study period only led to a marginal reduction in advanced tumor stages with reference to UICC stage distribution. Better oncological long-term results can be achieved in the first line, however, by detecting prognostically favorable early stages.

Analysis of the localization of the colon tumor dependent on the topographical location relative to the left colonic flexure (right-left comparison) should be taken into consideration during stratification for clinical studies, particularly for chemotherapy studies. The results also support the requirement for assessment of

\section{TABLE 4}

Estimation of the risk of developing anastomotic leakage

\begin{tabular}{l|l|l|l}
\hline Risk factor & Odds ratio & $\begin{array}{l}95 \% \text { confidence } \\
\text { interval }\end{array}$ & $p$-value \\
\hline Surgery duration & 1.003 & $1.002-1.004$ & $<0.001$ \\
\hline ASA risk score & 1.47 & $1.26-1.72$ & $<0.001$ \\
\hline Male sex & 1.58 & $1.37-1.83$ & $<0.001$ \\
\hline Ileus & 1.9 & $1.54-2.33$ & $<0.001$ \\
\hline Tumor in left colon & 1.45 & $1.28-1.73$ & $<0.001$ \\
\hline Cardiovascular diseases & 1.35 & $1.13-1.61$ & 0.0011 \\
\hline Valtrac anastomosis & 3.62 & $1.72-7.60$ & 0.0011 \\
\hline Single-layer manual anastomosis & 1.26 & $1.09-1.46$ & 0.0016 \\
\hline Intraoperative complication & 1.56 & $1.18-2.23$ & 0.0018 \\
\hline Hepatogenic diseases & 1.48 & $1.08-2.04$ & 0.0145 \\
\hline BMl category $>30 \mathrm{~kg} / \mathrm{m}^{2}$ & 1.2 & $1.01-1.44$ & 0.0366 \\
\hline
\end{tabular}

ASA. American Society of Anesthesiologists the entire colon both during diagnostics and colonoscopy screening (20).

An important finding during the evaluation of the laparoscopic procedure was that patients who were converted intraoperatively from a laparoscopic to an open procedure had worse early postoperative and oncological results (16). The conversion rate, which at $20.6 \%$ is too high, must be reduced. This can be achieved by better patient selection and an increase in case numbers for laparoscopic procedures per hospital $(p=0.021)$ (14). This implies, however, meaningful centralization of these procedures. This requirement is supported by evidence of the effect of hospital case volume on the rate of conversion (22).

The statements about anastomotic leakage, a procedure-specific postoperative complication with considerable influence on the overall quality of results, are highly important. Multiple regression analyses were able to identify factors that favor anastomotic leakage. With knowledge of these risk factors surgical techniques and the tactical approach can be specifically changed $(18,19)$. This yields findings for practical surgery which should not be underestimated. For example, this is relevant for single-layer suturing, which is an independent risk factor in the multiple analysis for the development of anastomotic leakage. In our opinion the identified risk is, however, too low to require doublelayer suturing in general. The technical aspects of anastomosis require, however, a high level of attention, particularly during further training. Even if the hospital's internal standard includes single-layer suturing, the double-layer suture technique should also be taught to ensure that surgeons have recourse to this method for appropriate risk constellations. In an emergency situation with ileus in the left colon caused by a carcinoma, primary anastomosis should only be indicated if the accompanying risk profile without simultaneous peritonitis is low and the tumor is easily resectable locally. In case of doubt, with advanced ileus and additional risk factors, decisions should be made knowing that anastomosis itself is a risk factor, which can be actively influenced, for discontinuous resection.

We have been able to identify important early postoperative and oncological long-term results for surgical treatment of colorectal carcinoma on the basis of these comprehensive, prospective, multi-center observational studies $(13,19)$.

With respect to quality assurance aspects of these investigations as part of clinical health services research, it must be stated that the concepts of voluntary participation and anonymity for all of the participating facilities guarantees the security of the reported data. Once a year the participating hospitals receive an evaluation of the patients they have enrolled compared to the entire study. This yields valid information about the quality of results with reference to the specific facility without the individual department having to fear any restrictions due to the reported data. Instead, based on the results of the study, each hospital is able to determine their own weaknesses and to work on constructively eliminating 
them. Voluntary participation indicates the sincere interest of the participating hospital in benchmarking to improve their own results. Anonymity combined with the use of modern statistical analysis strategies such as regression and stratification are instruments to enable the acquisition of data without selection bias and the confounding variables that skew results.

As a criticism of the methodology it must also be noted, however, that despite extensive plausibility tests, not all question complexes could be completely answered in all cases. An additional potential source of errors is the transfer of the data from the case report forms into the electronic database. In light of the large amount of data collected, incidental errors can be assumed, although a mechanism to check for these errors is missing. It must be noted that among the problems associated with the collection of the long-term results, $13 \%$ of the patients declined to consent to collection of follow-up data, for example. Due to the voluntary nature of participation, a definitive statement about whether the data collected are representative for all hospitals in Germany cannot be made.

The present data about quality measurement and transparency derived from health services research could form the basis for fees based on quality, as striven for by health care policy in Germany. The health insurance providers themselves are increasingly uninterested in the flood of dubious certifications but are much more interested in scientifically based, cross-sector quality assurance with ongoing verification of the quality of results (23).

\section{Conflict of interest statement}

The authors declare that no conflict of interest exists according to the guidelines of the International Committee of Medical Journal Editors.

Manuscript received on 14 January 2010, revised version accepted on 15 March 2010.

Translated from the original German by language \& letters.

\section{REFERENCES}

1. Benson K, Hartz AJ: A comparison of observational studies and randomized, controlled trials. N Engl J Med 2000; 342: 1878-86.

2. Gastinger I, Koch A, Marusch F, Schmidt U, Köckerling F, Lippert H: Bedeutung prospektiver multizentrischer Beobachtungsstudien für den Erkenntnisgewinn in der Chirurgie. Chirurg 2002; 73: 161-6.

3. Sørensen HT, Lash TL, Rothman KJ: Beyond randomized controlled trials: a critical comparison of trials with nonrandomized studies. Hepatology 2006; 44: 1075-82.

4. Ligthelm RJ, Borzì V, Gumprecht J, Kawamori R, Wenying Y, Valensi $\mathrm{P}$ : Importance of observational studies in clinical practice. Clin Ther 2007; 29: 1284-92

5. Rawlings D: DE Testimonio. On the evidence for decisions about the therapeutic interventions. The Haveian Oration. http://bookshop.rcplondon.ac.uk/contents/pub262-9bc950aa00e6-4266-8e80-e4bc63a25262.pdf

6. Furlan AD, Tomlinson G, Jadad AA, Bombardier C: Methodological quality and homogeneity influenced agreement between randomized trials and nonrandomized studies of the same intervention for back pain. J Clin Epidemiol 2008; 61: 209-31.

7. Ptok H, Marusch F, Schmidt U, Gastinger I, Wenisch HJC, Lippert H: Risk adjustment as basis for rational benchmarking: The example of colon carcinoma. WJS 2010 (in press) DOI 10.1007/s00268-010-0796-6

\section{KEY MESSAGES}

- Data from multi-center quality assurance studies enable statements to be made about comprehensive quality of medical care for colon carcinoma.

- To date, colonoscopy screening has only led to a marginal reduction in advanced tumor stages.

- A correlation between procedure frequency and early and late results could not be demonstrated for colon carcinoma.

- During the evaluation of laparoscopic procedures conversion was identified as a risk for a worse early postoperative and oncological result.

- Anastomotic leakage increases hospital mortality and is associated with a clearly worse oncological long-term course.

8. Hammer GP, du Prel JP, Blettner M: Avoiding bias in observational studies - part 8 of a series on evaluation of scientific publications. Dtsch Arztebl Int 2009; 106: 664-8.

9. Rochon PA, Gurwitz JH, Sykora K, et al.: Reader's guide to critical appraisal of cohort studies: 1. Role and design. BMJ 2005; 330: 895-7.

10. Mamdani M, Sykora K, Li P, et al.: Reader's guide to critical appraisal of cohort studies: 2. Assessing potential for confounding. BMJ 2005; 330: 960-2.

11. Normand SL, Sykora K, Li P, Mamdani M, Rochon PA, Anderson GM: Readers guide to critical appraisal of cohort studies: 3 . Analytical strategies to reduce confounding. BMJ 2005; 330: 1021-3.

12. Marusch F, Koch A, Schmidt U, et al.: Prospektive Multizenterstudie Kolon/Rektumkarzinome (Primärtumor). Zentralbl Chir 2002; 127: 332-49.

13. Kube R, Ptok H, Wolff S, Lippert H, Gastinger I for study group colon/rectum carcinoma (primary tumour): Quality of medical care in colorectal cancer in Germany. Onkologie 2009; 32: 25-9.

14. Kube R, Ptok H, Steinert R, et al.: Stellenwert der laparoskopischen Chirurgie des Kolonkarzinoms in der klinischen Routine. Chirurg 2008; 79: 1145-50.

15. Ptok H, Marusch F, Kuhn R, Gastinger I, Lippert H. Influence of hospital volume on the frequency of abdominoperineal resections and long-term oncological outcomes in low rectal cancer. Eur J Surg Oncol 2007; 33: 854-61.

16. Ptok H, Kube R, Schmidt U, Köckerling F, Gastinger I, Lippert H for the "colon/rectum carcinoma (primary tumor)" study group: Conversion from laparoscopic to open colonic cancer resection-associated factors and their influence on long-term oncological outcome. Eur J Surg Oncol 2009; 35: 1273-9.

17. Kube R, Mroczkowski P, Steinert R, et al.: Risikofaktoren für die Entstehung von Anastomoseninsuffizienzen nach Kolonkarzinom-Resektionen. Eine multiple Analyse von 844 Patienten mit postoperativer Nahtinsuffizienz. Chirurg 2009; 80: 1153-9.

18. Gastinger I, Marusch F, Koch A, et al.: Die Hartmann-Operation Wann ist sie beim kolorektalen Karzinom noch indiziert? Chirurg 2004; 75: 1191-6.

19. Lippert H, Gastinger I: Versorgung von Patienten mit Rektumkarzinomen in Deutschland. Dtsch Arztebl 2006; 103: 2257-62.

20. Benedix F, Kube R, Ptok H, et al.: Comparision of 17641 patients with right- and left-sided colon cancer: Differences in epidemiology, perioperative course, histology and survival. Dis Colon Rectum 2010; 53: 57-64. 
21. Kube R, Mroczkowski P, Granowski D, et al. for study group Quality assurance in primary colorectal carcinoma: Anastomotic leakage after colon cancer surgery: a predictor of significant morbidity and hospital mortality, and diminished tumour-free survival. Eur J Surg Oncol. 2010; 36: 120-4.

22. Kuwabara K, Matsuda S, Fushimi K, Ishikawa KB, Horiguchi H, Fujimori K: Impact of hospital case volume on the quality of laparoscopic colectomy in Japan. J Gastrointest Surg 2009 13: 1619-26.

23. Leber WD (2010) Der Chirurg BDC 1: 10-14. (letter to the editor)

\section{Corresponding author}

Prof. Dr. med. Ingo Gastinger

An-Institut für Qualitätssicherung in der operativen Medizin

Otto-von-Guericke-Universität Magdeburg

Leipziger Str., 4439120 Magdeburg, Germany

i.gastinger@ctk.de 